from the varying effects of shadows which make the study of the moon itself possible only to specialists. With the advance which has taken place in the interpretation of topographic forms in the last twenty years, it seems not too much to hope, now that this model has been made accessible to students of science, that its study will bring to light new facts regarding the nature and history of our satellite..

Oliver C. Farrington.

Field Columbian Museum, Chicago.

\section{LEHMANN AND HANSEN ON 'THE TELEPATHIC PROBLEM.'}

To The Editor of ScIENce: I can assure Professor James that I do not knowingly leave unread anything that he or Professor Sidgwick writes. I carefully considered the two papers to which he refers, at the time of their appearance, and have recently turned to them again. I am afraid, however, that I cannot make the admission that Professor James expects. Even if I granted all the contentions of criticism and report I should still see no reason to change the wording of my reference to Lehmann and Hansen. But there is a great deal that I cannot grant. While, like Stevenson's Silver, 'I wouldn't set no limits to what a virtuous character might consider argument,' I must confess that, in the present instance, the grounds for such consideration have not seldom escaped me.

Professor James rules that the Phil. Studien article is 'exploded.' I have tried to take up the position of an impartial onlooker; and, from that position, I have seen Professor James and Professor Sidgwick and Herr Parish handling the fuse, but I have not yet heard the detonation.

\section{E. B. Titchener.}

\section{ASTRONOMICAL NOTES.}

THE NOVEMBER METEORS.

REPORTS of meteor observations made this year between the 11th and 16th have been published from England, France and the United States. These are sufficient to show the characteristics of the display and to furnish hints as to the methods which should be followed in future years. The greatest number of meteors was noted on the morning of the 15th (civil reckoning), when the rate reached two each minute at some stations in the United States. A single observer could count forty or more per hour. It is probable that the maximum had already passed, as more meteors were noted on the preceding than on the following night at the few stations where the skies were clear on those nights. On the 14th a single observer at Lyons, France, noted 134 between 1:04 a. m. and 4:05 a. m. On account of the cloudy weather at Paris M. Janssen made a balloon ascension and observed above the clouds. We are told that this plan of securing clear skies will be used more extensively next year. The number observed this year is fully ten times as great as those observed in 1897 and is about the same as that noted at Grenwich in 1865, the year preceding the great shower of 1866. This augurs well for the year 1899.

Observers report several interesting facts: (1) Many meteors with the characteristics of the Leonids did not proceed from the radiant area within the 'Sickle of Leo.' The discrepancies in locating the radiant point are not to be wholly explained by the errors to which all eye estimates of meteor tracks are liable, but are in part real. (2) The radiant area has for its center a point which is farther south than that calculated from the observations of 1866 , which was R A. 10 h. 0 min., Decl. $+22^{\circ} .9$. The records this year, as far as known, range between 9 h. 50 min. and $10 \mathrm{~h} .20 \mathrm{~min}$. in R. A. and $+18^{\circ}$ to $22^{\circ}$ in Decl. A preliminary determination from the photographed trails of four meteors made at Harvard Observatory gives 10 h. 6.8 min., Decl. $+22^{\circ} 16^{\prime}$. (3) There were very few brilliant meteors compared with the total number. At Providence fourteen only out of nearly five hundred were brighter than the first magnitude.

The practicability of the photographic method of studying meteors needed no demonstration, but its possibilities are greater than was supposed. An ordinary camera, such as those in use by amateurs, will photograph the brighter meteors. Thus one with an aperture of only one inch and focal length of nine inches, if carefully focussed, will give trails of meteors as bright as the 0 magnitude. The camera need 